\title{
Correction to: Identification of TBX15 as an adipose master trans regulator of abdominal obesity genes
}

David Z. Pan 1,2, Zong Miao ${ }^{1,2}$, Caroline Comenho ${ }^{1}$, Sandhya Rajkumar 1,3, Amogha Koka', Seung Hyuk T. Lee ${ }^{1}$, Marcus Alvarez ${ }^{1}$, Dorota Kaminska ${ }^{1,4}$, Arthur Ko ${ }^{5}$, Janet S. Sinsheimer ${ }^{1,6}$, Karen L. Mohlke ${ }^{7}$, Nicholas Mancuso ${ }^{8}$, Linda Liliana Muñoz-Hernandez ${ }^{9,10,11}$, Miguel Herrera-Hernandez ${ }^{12}$, Maria Teresa Tusié-Luna ${ }^{13}$, Carlos Aguilar-Salinas ${ }^{10,11}$, Kirsi H. Pietiläinen ${ }^{14,15}$, Jussi Pihlajamäki ${ }^{4,16}$, Markku Laakso ${ }^{17}$, Kristina M. Garske ${ }^{1}$ and Päivi Pajukanta ${ }^{1,2,18^{*}}$

Correction to: Genome Med 13, 123 (2021)

https://doi.org/10.1186/s13073-021-00939-2

It was highlighted that in the original article [1] the UK Biobank Resource Application Number was incorrect (3934). The correct UK Biobank Resource Application Number is 33934. The authors also wished to add this sentence to their Acknowledgments section: "This research was conducted using the UK Biobank Resource under application 33934." The original article has been updated.

\footnotetext{
Author details

'Department of Human Genetics, David Geffen School of Medicine at UCLA, Los Angeles, USA. ${ }^{2}$ Bioinformatics Interdepartmental Program, UCLA, Los Angeles, USA. ${ }^{3}$ Computational and Systems Biology Interdepartmental Program, UCLA, Los Angeles, USA. ${ }^{4}$ Institute of Public Health and Clinical Nutrition, University of Eastern Finland, Kuopio, Finland. ${ }^{5}$ Department of Medicine, David Geffen School of Medicine at UCLA, Los Angeles, USA. ${ }^{6}$ Department of Computational Medicine, David Geffen School of Medicine at UCLA, Los Angeles, USA. 'Department of Genetics, University of North Carolina at Chapel Hill, Chapel Hill, North Carolina, USA. ${ }^{8}$ Center for Genetic Epidemiology, Department of Preventative Medicine, Keck School of Medicine, University of Southern California, Los Angeles, USA. ${ }^{9}$ Tecnologico de Monterrey, Escuela de Medicina y Ciencias de la Salud, Ave. Morones Prieto 3000, Monterrey, N.L., México 64710. ${ }^{10}$ Unidad de Investigación de Enfermedades Metabólicas, Instituto Nacional de Ciencias Médicas y Nutrición Salvador Zubirán, Mexico City, Mexico. ${ }^{11}$ Departamento de Endocrinología y Metabolismo del Instituto Nacional de Ciencias Médicas y
}

Nutrición Salvador Zubirán, Mexico City, Mexico. ${ }^{12}$ Departamento de Cirugía, Instituto Nacional de Ciencias Médicas y Nutrición, Mexico City, Mexico.

${ }^{13}$ Unidad de Biología Molecular y Medicina Genómica, Instituto de Investigaciones Biomédicas UNAM/ Instituto Nacional de Ciencias Médicas y Nutrición Salvador Zubirán, Mexico City, Mexico. ${ }^{14}$ Obesity Research Unit, Research Program for Clinical and Molecular Metabolism, Faculty of Medicine, University of Helsinki, Helsinki, Finland. ${ }^{15}$ Obesity Center, Endocrinology, Abdominal Center, Helsinki University Central Hospital and University of Helsinki, Helsinki, Finland. ${ }^{16}$ Department of Medicine, Endocrinology and Clinical Nutrition, Kuopio University Hospital, Kuopio, Finland. ${ }^{17}$ Department of Medicine, University of Eastern Finland and Kuopio University Hospital, Kuopio, Finland. ${ }^{18}$ Institute for Precision Health at UCLA, Los Angeles, USA.

Published online: 30 August 2021

\section{Reference}

1. Pan, et al. Identification of TBX15 as an adipose master trans regulator of abdominal obesity genes. Genome Med. 2021;13:123. https://doi.org/10.11 86/s13073-021-00939-2.
The original article can be found online at https://doi.org/10.1186/s13073021-00939-2.

*Correspondence: ppajukanta@mednet.ucla.edu

'Department of Human Genetics, David Geffen School of Medicine at UCLA, Los Angeles, USA

${ }^{2}$ Bioinformatics Interdepartmental Program, UCLA, Los Angeles, USA

Full list of author information is available at the end of the article

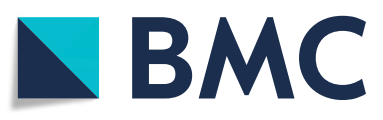

(c) The Author(s). 2021 Open Access This article is licensed under a Creative Commons Attribution 4.0 International License, which permits use, sharing, adaptation, distribution and reproduction in any medium or format, as long as you give appropriate credit to the original author(s) and the source, provide a link to the Creative Commons licence, and indicate if changes were made. The images or other third party material in this article are included in the article's Creative Commons licence, unless indicated otherwise in a credit line to the material. If material is not included in the article's Creative Commons licence and your intended use is not permitted by statutory regulation or exceeds the permitted use, you will need to obtain permission directly from the copyright holder. To view a copy of this licence, visit http://creativecommons.org/licenses/by/4.0/ The Creative Commons Public Domain Dedication waiver (http://creativecommons.org/publicdomain/zero/1.0/) applies to the data made available in this article, unless otherwise stated in a credit line to the data. 